\title{
Article
}

\section{Detecting nutrient deficiency in plant systems using synchrotron Fourier- transform infrared microspectroscopy}

Butler, Holly J., Adams, Steve, McAinsh, Martin R. and Martin, Francis L

Available at http://clok.uclan.ac.uk/17390/

Butler, Holly J., Adams, Steve, McAinsh, Martin R. and Martin, Francis L ORCID: 0000-0001-8562-4944 (2017) Detecting nutrient deficiency in plant systems using synchrotron Fourier-transform infrared microspectroscopy. Vibrational Spectroscopy, 90 . pp. 46-55. ISSN 0924-2031

It is advisable to refer to the publisher's version if you intend to cite from the work. http://dx.doi.org/10.1016/j.vibspec.2017.03.004

For more information about UCLan's research in this area go to http://www.uclan.ac.uk/researchgroups/ and search for <name of research Group>.

For information about Research generally at UCLan please go to http://www.uclan.ac.uk/research/

All outputs in CLoK are protected by Intellectual Property Rights law, including Copyright law. Copyright, IPR and Moral Rights for the works on this site are retained by the individual authors and/or other copyright owners. Terms and conditions for use of this material are defined in the policies page.

\section{CLoK}

Central Lancashire online Knowledge www.clok.uclan.ac.uk

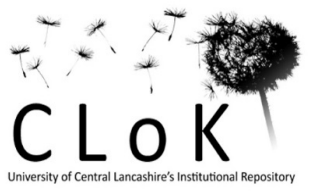




\section{Accepted Manuscript}

Title: Detecting nutrient deficiency in plant systems using synchrotron Fourier-transform infrared microspectroscopy

Authors: Holly J. Butler, Steve Adams, Martin R. McAinsh, Francis L. Martin

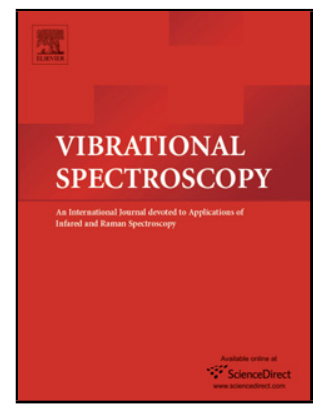

PII:

S0924-2031(16)30207-7

DOI: http://dx.doi.org/doi:10.1016/j.vibspec.2017.03.004

Reference: VIBSPE 2690

To appear in: VIBSPE

Received date: $\quad 30-8-2016$

Revised date: 13-3-2017

Accepted date: $\quad 14-3-2017$

Please cite this article as: Holly J.Butler, Steve Adams, Martin R.McAinsh, Francis L.Martin, Detecting nutrient deficiency in plant systems using synchrotron Fourier-transform infrared microspectroscopy, Vibrational Spectroscopyhttp://dx.doi.org/10.1016/j.vibspec.2017.03.004

This is a PDF file of an unedited manuscript that has been accepted for publication. As a service to our customers we are providing this early version of the manuscript. The manuscript will undergo copyediting, typesetting, and review of the resulting proof before it is published in its final form. Please note that during the production process errors may be discovered which could affect the content, and all legal disclaimers that apply to the journal pertain. 


\section{Detecting nutrient deficiency in plant systems using synchrotron Fourier-transform infrared microspectroscopy}

Holly J. Butler abc, Steve Adams ${ }^{\text {d }}$, Martin R. McAinsh ${ }^{\mathrm{e}^{*}}$, Francis L. Martin af*

${ }^{a}$ Centre for Biophotonics, Lancaster Environment Centre, Lancaster University, Lancaster LA1 4YQ, UK

${ }^{b}$ Centre for Global Eco-Innovation, Lancaster Environment Centre, Lancaster University, Lancaster LA1 4YQ, UK

${ }^{c}$ WESTChem, Department of Pure and Applied Chemistry, Technology and Innovation Centre, University of Strathclyde, Glasgow G1 1RD, UK

${ }^{d}$ Plant Impact Plc, Rothamsted, West Common, Harpenden, Hertfordshire, AL5 2JQ, $U K$

${ }^{e}$ Lancaster Environment Centre, Lancaster University, Lancaster LA1 4YQ, UK

${ }^{f}$ Division of Biosciences, School of Pharmacy and Biomedical Sciences, University of Central Lancashire, Preston PR1 2HE, UK

*Correspondence to: Holly Butler, WESTChem, Department of Pure and Applied Chemistry, Technology and Innovation Centre, University of Strathclyde, Glasgow G1 1RD, UK; Email: holly.butler@strath.ac.uk;

Prof Francis L. Martin, Division of Biosciences, School of Pharmacy and Biomedical Sciences, University of Central Lancashire, Preston PR1 2HE, UK; Email:

f.martin@lancaster.ac.uk; Tel.: +44(0)1524 510206

Dr Martin R. McAinsh, Lancaster Environment Centre, Lancaster University, Lancaster LA1 4YQ, UK; Email: m.mcainsh@lancaster.ac.uk; Tel.: +44(0)1524 510553 


\begin{abstract}
By 2050, it is estimated that the global population will have surpassed 9 billion people, presenting a significant challenge with regards to food security. In order to provide sufficient quantities of nutritious food in the future, it is necessary to improve agricultural productivity by up to $70 \%$. Nutrient deficiencies are one particular threat to food security that can have a negative impact on crop yield and quality. Currently the standard agricultural approach to prevention is to supply an excess macronutrient fertiliser, such as nitrate or phosphate, during crop production. However, the efficiency of this approach is poor as deficiencies of specific nutrients, such as $\mathrm{Ca}$, are not prevented in this circumstance, and fertiliser use is associated with a host of adverse environmental impacts. Herein, we describe a novel method to detect Ca deficiency using synchrotron radiation-based Fourier-transform infrared (FTIR) microspectroscopy in live and fixed tissue of the model plant Commelina communis, as a precursor to targeted nutrient remediation in the field.
\end{abstract}

Keywords: Calcium, Deficiency, Fourier-transform infrared (FTIR) microspectroscopy, Nutrient, Plant, Synchrotron radiation

\title{
1. Introduction
}

Food security can be defined as providing a constant supply of nutrition for all, in order to live a healthy lifestyle, regardless of social, economic and physical circumstances [1]. The expanding global population has increased demand for food of sufficient quality, and has further emphasised the challenge of maintaining food security in the modern era [2]. Climate change, competition for arable land, and agricultural productivity are significant factors affecting global food production [3]. Improving efficiency during crop production is an area where small alterations to farming practices, may result in largescale yield and quality increases. The difference between the attainable yield and the observed yield is known as a yield gap, and it is by reducing this deficit that agricultural productivity can be improved [4]. 
Plants require fourteen essential nutrients in order to grow optimally and produce the maximum attainable yield; these can be split into macro- (N, P, K, Ca, Mg and S) and micro- nutrients (B, Cl, Cu, Fe, Mn, Mo, N and Zn) [5]. Poor availability of one or more of these nutrients, can not only reduce the quantity of produce per hectare of land, but can also decrease food quality and shelf life. The use of nutrient fertilisers is a traditional practice of agricultural intensification that has been shown to increase yield (and thus reduce the yield gap) in crop species by between $30-50 \%$ [6]. Fertilisers containing primary macronutrients $(\mathrm{N}, \mathrm{P}$ and $\mathrm{K}$ ) are most commonly applied, as deficiencies in these elements are more commonplace in agricultural environments. However, it has been shown that use of such fertilisers is relatively inefficient and less than $50 \%$ of the nutrient applied is recovered in the produce output [7]. Furthermore, the use of fertilisers, such as $\mathrm{NH}_{4}$, has a number of detrimental effects on the environment, such as eutrophication from nitrate leaching, and also enormous carbon footprints associated with their production and application [8]. It is estimated that crop production, including farm operations, equates to the generation of around $769.4 \mathrm{~kg}$ of $\mathrm{CO}_{2}$, and its equivalents (such as $\mathrm{N}_{2} \mathrm{O}$ ), per hectare of farmland each year; of this total, over $90 \%$ is associated with fertiliser use [9]. It is also important to note that deficiencies in all nutrients can occur, with a diverse array of physiological symptoms and severities, which would not be remediated by the use of a generic N, P or K containing fertiliser [10].

Reduced Ca availability can have a significant impact on crop yield, due to the pivotal role this element has in structural stability within the plant tissues[11]. Ca pectate is a key component of plant cells walls and thus reduced availability of Ca can often result in degradation of the cell walls, particularly in developing and enclosed tissues, and those that are supplied predominantly by the phloem [12]. Ca is absorbed into the plant via the root system and transport is unidirectional in the xylem and transport is therefore dependent on the rate of transpiration [13, 14]. Consequently, rapidly growing tissues and fruit, are particularly susceptible to reduced $\mathrm{Ca}$ availability and therefore degradation. Ca deficiencies manifest in a range of crop species, from blossom end rot in tomatoes, tip burn in lettuce and bitter pit in apples and in some instances can result in up to a $50 \%$ loss of yield $[15,16]$. Although relatively uncommon in nature, due to intensive farming practises, $\mathrm{Ca}$ deficiencies are increasingly widespread in agricultural settings [17]. Due to the detrimental effect of this deficiency, as well as the role that $\mathrm{Ca}$ 
plays in fruit ripening, maintaining fruit firmness and reducing postharvest decay, $\mathrm{Ca}$ supplementation in agriculture is becoming an emerging section of the crop enhancement market [18]. This approach not only directly targets the nutrient status of the crop, but also reduces environmental impacts associated with $\mathrm{N}$-based fertilisers.

It has been proposed that accurate determination of the nutrient status of plants can be used to better understand and target the specific nutritional needs of crops [19, 20]. In doing so, nutrient use efficiency would be vastly improved as the appropriate nutrient can be applied as and when required, improving the agricultural productivity whilst also reducing financial and environmental burdens. Currently, crop nutrient status is determined by foliar and soil analyses using analytical techniques such as flame photometry and flame atomic absorption spectroscopy [21, 22]. Although these approaches derive elemental information to a high degree of sensitivity, they require a nutrient extraction step, usually via acid digestion, which can often be time-limiting and also removes any information regarding spatial origin and distribution [23]. It is evident that there is a need for a novel crop screening approach that is able to detect the effects of nutrient deficiency before any detrimental effects are observed, which can be rapidly acquired in the field without any effect on the plant, and without extensive sample preparation requirements.

Vibrational spectroscopy may be such a tool to fill this gap. It has been widely shown that infrared (IR) or Raman microspectroscopy can be used to characterise valuable plant substances, but can also be implemented to analyse in vivo and fixed plant tissues samples in order to monitor plant health [24-27]. The application of Raman microspectroscopy in plant research had been relatively limited due to intrinsic fluorescence issues found within tissues. However, analysis of live samples has recently been shown to effectively quench fluorescence due to the presence of water allowing the acquisition of high quality point spectra and spectral maps [24, 28]. Conversely, Fouriertransform IR (FTIR) microspectroscopy has been largely restricted to the interrogation of fixed plant samples, as water has a detrimental effect on the IR spectrum due to its strong dipole moment. This has been overcome by the use of attenuated total reflection (ATR) acquisition mode FTIR, which uses a refractive prism to attenuate the IR beam into the sample and has recently allowed the investigation of foliar tissues [29, 30]. 
The combination of FTIR microspectroscopy with synchrotron radiation (SR) can improve the spatial resolution and signal-to-noise ratio (SNR) achievable in comparison to conventional benchtop instruments that employ globar IR sources [31, 32]. This is because SR is up to 1000 times brighter than thermally produced IR radiation, and thus is delivered to the sample at high flux density [33]. SR-based FTIR (SR-FTIR) microspectroscopy may therefore shed light upon molecular changes at spatial resolutions $<10 \mu \mathrm{m}$, providing subcellular detail unachievable with traditional FTIR microspectroscopy [23, 34]. In plant research, SR-FTIR microspectroscopy has been employed to interrogate the molecular composition in a range of tissues including kernels, roots, and leaves [35-38]. The imaging capabilities of SR-FTIR have also been exploited to image the spatial distribution of cell wall components, and tissue microstructures [39-42]. As more information is derived using SR-FTIR at a cellular level, the technique represents a powerful tool for plant research and can be exploited in a range of stress determination studies, including biotic stresses such as pest and disease and abiotic stresses such as nutrient deficiency [43]. However, in contrast to the biomedical and material science fields, SR-FTIR has not been widely implemented in plant-based studies due largely to the aforementioned limitations of FTIR with water containing samples, which restricts in vivo analyses [35]. Nevertheless, it has been suggested that the high brilliance of a synchrotron light source, may overcome interference from water [44]. Water absorbs strongly at $\sim 1650 \mathrm{~cm}^{-1}$ and thus can result in a loss of spectral information in this important spectral region, often associated with the amide I of protein structure and composition. Therefore it may be possible to obtain spectra from live samples or samples in aqueous environments, when employing SR [45].

Herein we investigate the effects of $\mathrm{Ca}$ depletion on the model plant species Commelina communis using SR-FTIR microspectroscopy for pre-symptomatic detection of Ca deficiency. C. communis is commonly used to study intracellular signalling in stomatal guard cells due to the ease with which the abaxial epidermis in which the stomata are primarily located can be isolated from the leaves of this species [46]. In this investigation, this characteristic is exploited in order to examine the effects of sample preparation on deficiency detection by comparing freshly isolated tissue (unfixed) with chemically fixed tissue that is conventionally interrogated using FTIR and SR-FTIR microspectroscopy. 


\section{Material and Methods \\ 2.1 Plant growth conditions}

C. communis seeds were sown into rock wool cubes and supplied with distilled water until germination ( $\sim 10$ days). Seedlings were then transferred to purpose built hydroponic nutrient supply systems containing three distinct $\mathrm{Ca}$ concentrations (optimal $\mathrm{Ca}, 200$; low $\mathrm{Ca}, 100$, Ca deficient, 0 ppm), supplied using a modified Hoagland's solution for 21 days [47]. These treatments were chosen to mimic common nutrient requirements of agriculturally relevant crops such as Solanum lycopersicum. Each Ca treatment was replicated in three separate systems, each of which contained $16 \mathrm{~L}$ of nutrient solution and housed 6 seedlings from which three were randomly selected for analysis. Dissolved oxygen levels were maintained at $5.5 \pm 0.5 \mathrm{mg} / \mathrm{L}$ using aquatic air pumps (Boyu, China); conductivity at $2 \pm 0.1 \mathrm{mS}$; and $\mathrm{pH} 6.1 \pm 0.1$. Plants were grown $25 \pm 2{ }^{\circ} \mathrm{C} / 20 \pm 2{ }^{\circ} \mathrm{C}$, day / night; $16 \mathrm{~h}$ photoperiod; $150 \pm 25 \mu \mathrm{mol} \mathrm{m} \mathrm{m}^{-2} \mathrm{~s}^{-1}$ using $600 \mathrm{~W}$ metal halide lamps (Osram Ltd, UK) and transferred to the laboratory immediately prior to acquisition where they were maintained under similar conditions. The youngest, fully expanded leaves were excised from each four-week-old plant and were prepared for SRFTIR microspectroscopy or fixation immediately post-excision.

\subsection{Epidermis isolation for unfixed samples}

Isolated epidermis was prepared according to Weyers and Travis [48]. In short, a rectangular strip around $8 \mathrm{~mm}$ in width was cut from the lamina on either side of the major leaf vein using a sharp blade. A small incision was then placed onto the adaxial surface, without damaging the lower epidermal surface, creating a tab that can be carefully peeled backwards using forceps. The epidermal strip was then trimmed to a rectangular area $(\sim 8 \mathrm{~mm} \times 35 \mathrm{~mm})$ before being mounted on a $\mathrm{BaF}_{2}$ slide (Crystran Ltd, UK), with $50 \mu \mathrm{L}$ of $50 \mathrm{mM}$ KCL, $10 \mathrm{mM}$ Mes/KOH, pH 6.15 (KCl-Mes) buffer. Samples were then immediately analysed using SR-FTIR microspectroscopy.

\subsection{Sample fixation and embedding}

Formalin fixation followed by paraffin embedding was chosen as a model approach for sample preparation prior to SR-FTIR microspectroscopy, as this technique has been well implemented in plant and biomedical studies [41]. Rectangular leaf sections were first excised and immediately fixed in $10 \%$ formalin for $24 \mathrm{~h}$, dehydrated in an ethanol series 
(70, 90 and 100\%) for $6 \mathrm{~h}$, and placed into xylene for $1 \mathrm{~h}$. At each stage of fixation, the solution was changed twice.

To begin the embedding process, samples were transferred to molten paraffin wax at $60^{\circ} \mathrm{C}$ for $24 \mathrm{~h}$ to allow for sufficient wax infiltration. Samples were then orientated longitudinally in wax moulds in order to isolate the epidermis, and left to cool on ice for $30 \mathrm{~min}$. Sections were cut at a thickness of $5 \mu \mathrm{m}$ using a microtome, and placed into a warm water bath to allow expansion of the paraffin wax, before being floated onto a $\mathrm{BaF}_{2}$ slide. Samples were dewaxed using xylene for $1 \mathrm{~h}$, and hydrated using an ethanol series (100, 90 and 70\%) for $6 \mathrm{~h}$. Fixed samples were stored at room temperature $\left(20^{\circ} \mathrm{C}\right)$ until analysis.

\subsection{Synchrotron radiation- based FTIR microspectroscopy}

Spectra were obtained using a Bruker Vertex 80 V FTIR spectrometer coupled to a Hyperion 3000 microscope ( $\times 36$ objective and condenser), a $\mathrm{LN}_{2}$ cooled MCT detector, and the SR IR source, at the Multimode IR Imaging and Microspectroscopy (MIRIAM) beamline at Diamond Light Source, UK. An aperture size of $10 \mu \mathrm{m} \times 10 \mu \mathrm{m}$ was used to collect spectra at a spectral resolution of $4 \mathrm{~cm}^{-1}$ with 256 co-additions across the mid-IR region $\left(4000-600 \mathrm{~cm}^{-1}\right)$. Measurements were acquired in transmission mode as recent literature has identified its advantages over reflection measurements [49]. On average, 10 spectra were obtained per sample each live and fixed sample. A background measurement was taken from the substrate for every ten sample spectra to account for atmospheric conditions. Spectra were converted to absorbance units using OPUS 8 software (Bruker, UK).

\subsection{Globar-based FTIR microspectroscopy}

A Thermo Nicolet 6700 FTIR spectrometer coupled to a Nicolet Continu $\mu$ m microscope (Thermo Fisher Scientific, UK) and a $\mathrm{LN}_{2}$ cooled mercury cadmium telluride (MCT) detector was employed to acquire transmission IR measurements $\left(4000-650 \mathrm{~cm}^{-1}\right)$. Spectra were acquired using a 36x objective at a spectral resolution of $4 \mathrm{~cm}^{-1}$, with 256 co-additions, whilst background spectra were taken after every ten sample spectra. Spectra were converted to absorbance units using Omnic spectra software (Thermo Fisher Scientific, UK). 
Spectral analysis was conducted using the IRootLab Matlab toolbox (https://github.com/trevisanj/irootlab) unless otherwise stated [50]. Initially, spectra were quality tested using in-house written scripts to identify spectra with low SNR and potential outliers. The number of features within each spectrum was then reduced by focusing on the fingerprint region $\left(1800-900 \mathrm{~cm}^{-1}\right)$ as this is where biological molecules are known to absorb IR [51]. Spectra were first order differentiated $\left(1^{\text {st }}\right.$ order polynomial) with Savitzy-Golay smoothing, and vector normalised to account for confounding sample characteristics such as thickness. For biomarker extraction using first derivative data, the point at which the spectra cross the zero line will represent the peak maxima from the original spectra and thus these values are used throughout. Absorbance alterations can be interpreted by observing the slope across the zero line; with an increase in absorbance shown by a sharper slope.

\subsection{Multivariate analysis}

Exploratory principal component analysis (PCA) was conducted on the mean centred data in order to reduce the dataset down to factors that accounted for underlying variance in the spectra. This output was then fed in linear discriminant analysis (LDA), to minimize intra-class differences and maximises inter-class separation, and therefore give optimum separation of the dataset classes. The number of principal components used were optimized using the PCA pareto tool in IRootLab; this was determined as the 'elbow' point of the cumulative variance plot and always accounting for $>95 \%$ of the variance in the dataset [52]. This process was cross validated using $10 \mathrm{k}$-folds and a leave-one-out approach, to prevent overfitting of the data. Classification of spectral classes was conducted using a PCA-linear discriminant classifier (LDC) with the same validation parameters.

\subsection{Statistical Analysis}

A Mann-Whitney 'U'-test per wavenumber was conducted to compare spectral differences in pre-processed data at a confidence interval of 0.01 . This approach was conducted on loadings plots as derived from PCA-LDA to derive spectral regions that discriminated between $\mathrm{Ca}$ treatments. 


\section{Results \& Discussion}

\subsection{Unfixed and fixed tissue}

As it is possible to derive meaningful spectra from water containing samples, we look to compare the reproducibility and suitability of both fixed and unfixed (ex vivo) plant tissue samples for identifying Ca nutrient deficiency. Figure 1A presents representative bright field image of freshly prepared isolated abaxial epidermis in which the stomatal pores, surrounded by a pair of guard cells (GCs; identified with an arrow), and subsidiary and epidermal cells (ECs) are clearly visible. This contrasts markedly with the representative sample from fixed leaf tissue shown in Figure 1B. In order to produce a sample appropriate for transmission FTIR measurements, paraffin embedded tissue must be sectioned to a thickness no greater than $12 \mu \mathrm{m}$ [53]. During this process it is challenging to construct a sample that contains both epidermal and guard cells. The GCs surrounding the open stomatal pore are clearly visible in Figure 1B; the surrounding material is likely to be derived from the spongy mesophyll, which can be recognised by the irregular cell architecture of this tissue that is necessary to allow the movement of gas within the internal airspaces of the leaf. As a consequence of this, only stomatal GCs are probed in fixed leaf tissue samples for the remainder of this study, whilst both guard and epidermal cells are investigated in live tissue.

In regards to the biochemical alterations that occur due to chemical fixation, clear differences can be observed between unfixed and fixed samples (Fig. 2, Table 1). It is preferable to remove any paraffin wax from samples prior to spectral acquisition due to the strong absorbance of the wax in the fingerprint. However, many dewaxing protocols have been shown to have significant effects on the resultant spectra obtained, particularly in regard to lipids [54]. This is evident when comparing fixed and unfixed plant tissue, where a decrease in lipid absorbance at $1740 \mathrm{~cm}^{-1}$ can be seen following fixation and dewaxing. The absorbance profiles of key cell wall polysaccharides are also stronger in live tissues, shown predominantly at 1416 and $1356 \mathrm{~cm}^{-1}$. GC cell walls characteristically contain more phenolic esters of pectins than the surrounding cells, which is more effectively differentiated when using unfixed samples [55]. Fixed tissues displayed an increased absorbance at the amide II region, whilst live tissues depicted a higher absorbance at $1533 \mathrm{~cm}^{-1}$, showing widespread protein alterations in the spectra. 
This effect may be tentatively associated with protein cross-linkages as a consequence of formalin fixation [56]. Overall, a slight reduction in signal strength can be observed in live tissues, which may be due to underlying water interference and a lower concentration of biological material compared to fixed samples which are dehydrated.

\subsection{Guard cells versus epidermal cells}

GCs are crucial for the regulation of gas exchange (uptake of $\mathrm{CO}_{2}$ for photosynthesis and loss of water via transpiration) in plants [64]. This is mediated by rapid alterations in the water content of the GC in response to external stimuli, driven by fluxes of osmotically active anion and cations and controlled by a well characterised signalling network [65]. An increase in GC turgor pressure results in the opening of the stomatal pore, thus promoting gas and water exchange, whilst a reduction in turgor pressure closes the stomatal pore[66]. These cells are therefore key indicators of stress and have been studied in response to a range of biotic and abiotic stresses [46, 67-69]. The surrounding ECs act as a barrier to internal and external environments and thus have a relatively simple function in comparison to GCs and consequently, the biochemical composition of stomatal GCs are distinctly different from the surrounding ECs [55]. Here we investigate the suitability of GCs as a target in plant monitoring studies using vibrational spectroscopy by observing the effects of Ca deficiencies on these tissues.

When comparing derivative spectra obtained from GCs and ECs in unfixed tissue, distinct difference in cell wall materials can be seen, particularly regarding cellulosic polysaccharides (Fig. 3A). Increased absorbance at 1740, 1246, and $1049 \mathrm{~cm}^{-1}$ corresponding to celluloses and lignins in GCs corresponding to the differentially thickened cell walls in these cells, up to $5 \mu \mathrm{m}$ across compared to the 1-2 um typical of ECs, that is essential to GC function (Table 1) [66]. Increased absorbance at the amide I band at $1637 \mathrm{~cm}^{-1}$, also indicates a markedly different protein content in GCs compared to ECs which may be due to the varying functions of each cell, with GCs responding dynamically to changes environmental conditions, whereas epidermal cells require a constant protein conformation to maintain overall leaf structure. Interestingly, the levels of unesterified pectins, another crucial cell wall component, are considerably higher in the epidermis, which has also been observed in other studies [55]. This could be 
indicative of the ordered structure of epidermal tissues, which are maintained by $\mathrm{Ca}-$ pectin cross-linking that provides structural support to the leaf.

As a preliminary step to compare the suitability of GCs versus ECs as targets for monitoring nutrient deficiencies, exploratory multivariate analysis was conducted on the data (Fig. 3B). The 2D PCA-LDA scores plot examines the differences between the three Ca treatments, and whether any effects are more apparent in GCs or ECs. It is clear that Ca treatments are separated well in both PC1 and PC2, with some small overlap between treatments, showing that there is an observable alteration in the spectra as a consequence of $\mathrm{Ca}$ depletion, which is further investigated later in this study. With regards to the two target tissues, both GC and the epidermis tend to separate almost identically with the Ca stress, indicating that both tissues are potentially suitable targets for nutrient screening. An optimum level of $\mathrm{Ca}$ in this study is defined as $200 \mathrm{ppm}$, and this class of data significantly $(P<0.001)$ separates from depleted treatments in LD1, whereas differences between depleted samples separate in LD2. Within the control treatment cluster, there are some subtle differences between GC and the epidermis although this separation is not visible in lower Ca treatments. This may be due to fundamental alterations associated with $\mathrm{Ca}$ stress overhauling the sensitive variance differences between guard and epidermal cells.

\subsection{Ca deficiency}

The effects of $\mathrm{Ca}$ availability in the growth environment (optimal $\mathrm{Ca}, 200 \mathrm{ppm}$; low $\mathrm{Ca}$, 100 ppm; Ca deficient, 0 ppm) on the SR-FTIR spectra obtained from living and fixed tissues from $C$. communis was examined to determine the spectral alterations indicative of nutrient deficiency, and whether this spectral information is sufficient to accurately identify plants undergoing nutrient stress.

The processed spectra from each of the tissues exposed to three $\mathrm{Ca}$ environments, depict clear absorbance alterations throughout the fingerprint region (Fig. 4; Table 1). In both ex vivo tissues and fixed tissue samples, absorbance bands associated with proteins are shown to decrease consistently in response to Ca deficiency, specifically around the Amide I region (1635 and $\left.1630 \mathrm{~cm}^{-1}\right)$ and Amide II $\left(1522\right.$ and $\left.1487 \mathrm{~cm}^{-1}\right)$ regions. This observation is more apparent in spectra acquired from unfixed tissues (Fig. 4A and 4B), 
in comparison to fixed tissue (Fig. 4C), which in this case is associated with the formalin fixation process. As mentioned previously, this sample preparation step can result in protein cross linkages and may therefore increase protein stability at the point of spectral acquisition. An overall reduction in protein absorbance may be indicative of a compromised structure, and possible be an earlier indicator of senescence [24].

Furthermore, widespread polysaccharide absorbance differences can be seen across all samples as a consequence of Ca stress. In fixed samples, these differences are limited to the lower wavenumber region between $1200-1050 \mathrm{~cm}^{-1}$, whereas in unfixed tissues, both GCs and the epidermis, these alterations manifest around $1550-1250 \mathrm{~cm}^{-1}$. Many valuable plant substances have characteristic IR bond vibrations across the whole spectrum and there are few regions specific to a given biomolecule, thus this is unlikely to be due to a single molecule. However, this difference may again imply details about the chemical fixation process on plant tissue prior to IR spectroscopic analysis, as fixation has had a substantial impact on bond vibrations in the lower wavenumber region, where simple bending vibrations are found [70]. It is evident from Figure 4, that the absorbance of pectin-related IR bands (1728, 1354 and $\left.1097 \mathrm{~cm}^{-1}\right)$ increases due to Ca deficiency, and may indicate an increased production of structural polymers to accommodate the reduction in structural $\mathrm{Ca}$ pectate. The peak at $1354 \mathrm{~cm}^{-1}$ however can be seen to be lowest in the intermediate Ca treatment (100 ppm), which may suggest a stress response to moderate nutrient stress - although this would require further investigation. In contrast, absorbance bands associated with cellulosic compounds $\left(1246 \mathrm{~cm}^{-1}\right)$ illustrate a clear decline due to Ca deficit. Similar to protein absorbance, this may be symptomatic of a decrease in tissue viability, as cell wall growth and expansion is hampered due to lack of $\mathrm{Ca}$.

Cross-validated PCA-LDA, using a leave-one-out approach, was conducted on the spectral data in order to maximise the interclass differences, and separate data based upon the nutrient availability [78]. Fig. 5 depicts the 2D scores plots from this data reduction step, and the consequent loadings plots transformed from this data, indicating spectral regions where variance is apparent in the dataset, as described by Martin et al. [79]. Tentative band assignments for spectral peaks described as accountable for variance in the dataset can be seen in Table 2 . 
Initially, spectra obtained from GCs of unfixed epidermal peels, separate strongly with regards to Ca depletion (Fig. 5A). The control treatment of $200 \mathrm{ppm}$ is almost entirely separated from low Ca treatments in LD1, whist low Ca treatments are distinguishable in LD2. This may indicate that the general response of the plant to $\mathrm{Ca}$ deficiency is readily observable compared to optimum Ca conditions, whereas a subtle, yet still discernible, difference may be found in the response to different levels of $\mathrm{Ca}$ deficiency. With regards to exact wavenumber regions where variance can be found between Ca treatments, observations in the loadings of LD1 and LD2 may shed light on these subtle differences. LD1 indicates major differences around the polysaccharide region at $1055 \mathrm{~cm}^{-1}$, likely to be correlated to pectin absorbance (Fig. 5B). A decrease in $\mathrm{Ca}$, would substantially affect the Ca pectate levels in the plant tissues, and thus this response is as expected between the optimal and $\mathrm{Ca}$ deficient treatments. Alterations in $v(\mathrm{C}=\mathrm{O})$ are also evident in the loadings, which can be assigned to both lignin and protein contributions to the spectrum, possibly highlighting a structural compensation as a consequence of integrity loss. The same response can be seen in LD2; however, the most discriminatory spectral region in this curve is attributed to polysaccharides. This could potentially imply that this region may be used to discriminate between levels of $\mathrm{Ca}$ deficiency, in this targeted group of cells.

In order to determine the diagnostic potential of this study, a PCA-LDC was conducted on the sample data, which was shown to positively classify Ca deficient, low Ca and optimal Ca samples at a rate of 100, 93.75, and 96.15\% respectively (Table 3). This is promising in regards to future studies on large datasets taken from field data, which will likely be highly variable in comparison to a laboratory based investigation. It is important to note that the use of SR-FTIR for studies in planta in the field would be impossible, and so the use of a less powerful technique, such as standard globar-based FTIR microspectroscopy, may not provide such high levels of accuracy. As such it is encouraging that near perfect classification is possible with the highly sensitive SR-FTIR approach. Additionally, one difficulty with detection and consequent remediation of nutrient deficiencies is that they are often co-dependent upon the availability of other nutrients, yet such a high accuracy rate even for intermediate deficiency samples is promising $[80,81]$. As such, it may be possible to identify nutrient deficiencies in the field and instigate a targeted nutrient remediation process. 
Spectra obtained from living epidermal tissues exhibit a similar degree of separation within a 2D PCA-LDA scores plot, although it is the low (100 ppm) Ca treatment that separates on LD1, and the optimal (200 ppm Ca) and deficient (0 ppm Ca) treatments that separate effectively in LD2 (Fig. 5C \& 5D). Loadings derived from this dataset correlate with findings in analysis of live GCs, that depict that the low $\mathrm{Ca}$ treatment is identifiable by protein differences, specifically at the Amide III region, shown in LD1. Additionally, deficient and optimal Ca treatments can be primarily isolated due to Amide I protein alterations. As shown earlier in this study, epidermal tissue has distinctly less polysaccharide content, and thus spectral alterations as a consequence of $\mathrm{Ca}$ depletion are less likely to be visible in the absorbance of these molecules. Despite this, the rate of classification in this dataset remains high at 100, 93.10 and 95.83\% for deficient, low and optimal Ca treatments (Table 3). This indicates that epidermal tissue is marginally less efficient at identifying Ca deficiencies than GCs; however, this is a minimal reduction in efficiency and is likely insignificant.

In fixed tissue, 2D PCA-LDA scores plots indicate an almost identical separation pattern to that seen in multivariate analysis of spectra from live GCs, with the optimal Ca treatment effectively separating in LD1 (Fig. 5E). There is a larger degree of overlap between $\mathrm{Ca}$ treatment groups in fixed tissue, and may indicate enhanced difficulty at detecting subtle biological changes as a consequence of $\mathrm{Ca}$ depletion. This is further highlighted in looking at the classification accuracy within this dataset in Table 3, which depicts reduced identification of samples grown in $\mathrm{Ca}$ deficient conditions, at a rate of $75.84 \%$. This class is particularly spread in the scatterplot, indicating increased variability in these samples which may suggest that the fixation process had a greater detrimental effect upon the Ca deficient samples. The optimal Ca treatment groups together relatively tightly in comparison, reflected by a high classification rate of $99.43 \%$.

Loading plots derived from this dataset exhibit a striking response in LD1 and 2, with the former highlighting spectral alterations solely below $1200 \mathrm{~cm}^{-1}$, and the latter exclusively above $1300 \mathrm{~cm}^{-1}$ (Fig. 5F). As a consequence, the optimal Ca treatment that is clearly distinguishable in LD1, is primarily segregated due to variance in polysaccharides, particularly cellulose. The differences between the Ca deficient and low 
Ca treatments shown in LD2, can be correlated predominantly with protein alterations, and also pectin and lignin molecules. The pattern displayed here in fixed tissue correlates with the differences observable in spectra derived from in vivo measurements of GCs, that show that the major differences in spectra explained by LD1, are largely attributed to polysaccharide alterations. This is intuitive due to the known effect of Ca deficiency on tissue structure; that as the Ca availability reduces, less Ca pectate is found in tissues, which may be responsible for the large polysaccharide changes we observe here. Also, alterations in cellulose and other cell wall carbohydrates such as arabinose and galactose levels may be an indicator of increased production to account for weaknesses in tissue structure as a consequence of $\mathrm{Ca}$ depletion [82].

\section{Conclusions}

The use of SR-FTIR for plant-based studies has, to date, been relatively underdeveloped as the strong absorption of water in the fingerprint region can often conceal spectral information, particularly in live tissue samples. In this study, we investigated the ability of such an approach to identify Ca deficiencies in both living and fixed tissue, to determine how accurately this can be determined prior to the appearance of nutrient deficiency symptoms. Due to the high flux density of SR, the interference from water can be minimised, allowing sampling from isolated epidermal tissues. The ability to sample from living tissues, is promising for further investigations using SR-FTIR in planta, and also prevents the need to fix tissue samples, which is both time consuming and detrimental to the spectral output, including the ability to detect Ca deficiencies.

Using this approach, it is possible to differentiate between specific cell types on the abaxial leaf surface of leaves by observing increased levels of absorbance in cellulosic compounds in GCs compared to ECs. In order to determine a standard approach for crop screening in the field, it is first important to establish an ideal target for spectroscopic analysis. Initially, leaves are an ideal focus as they are relatively disposable, and readily exhibit symptoms of stress; however, the heterogeneity of such tissues indicates the need to identify a sole target for screening. Using the highly specific approach of SR-FTIR, both GCs and ECs performed equally well in detection of $\mathrm{Ca}$ deficiency prior to symptom onset, and were able to identify both low $\mathrm{Ca}$ and $\mathrm{Ca}$ deficient treatments at above $90 \%$ classification accuracy. As both cell types were uniform in their suitability, it could indicate that the whole epidermis of a leaf could be 
an ideal target for field trials observing nutrient deficiencies. As a prerequisite for such trials, the proficiency at which a globar based FTIR study is able to accurately detect Ca deficiencies is needed.

In this study, we show that SR-FTIR as a crop screening tool, is able to accurately determine the $\mathrm{Ca}$ nutrient status of $C$. communis leaf samples grown at a range of $\mathrm{Ca}$ availabilities. Such a technique would not only be highly beneficial for wider nutrient screening applications, but also for identifying other abiotic stresses such as ozone damage, and biotic stresses including pest infestations [30]. In doing so, the overall efficiency of our agricultural practises can be improved with targeted remediation, that will increase yield and contribute towards the global food security.

\section{Acknowledgements}

The authors acknowledge the Science \& Technology Facilities Council (STFC) for allowing access to the Diamond Light Source Ltd, at Rutherford Appleton Laboratories in Oxfordshire. Thanks also go to the beamline B22 MIRIAM and Gianfelice Cinque, Mark Frogley, and Katia Wehbe for their technical guidance during these experiments (SM9755-1, SM9755-2). HJB is a member of the Centre for Global Eco-Innovation funded by the European Union Regional Development Fund. This project is in collaboration with Plant Impact Plc. Special thanks to Dionysios Touliatos for his guidance with hydroponic plant cultivation. 


\section{References}

[1.] Mechlem K, European Law Journal 10 (2004) 631-648.

[2.] Godfray HCJ, Beddington JR, Crute IR, Haddad L, Lawrence D, Muir JF, et al., science 327 (2010) 812-818.

[3.] Rosegrant MW, Cline SA, Science 302 (2003) 1917-1919.

[4.] Licker R, Johnston M, Foley JA, Barford C, Kucharik CJ, Monfreda C, et al., Global ecology and biogeography 19 (2010) 769-782.

[5.] Roy R, Finck A, Blair $\mathrm{G}$, Tandon $\mathrm{H}$, A guide for integrated nutrient management FAO Fertilizer and Plant Nutrition Bulletin 16 (2006) 368.

[6.] Stewart W, Dibb D, Johnston A, Smyth T, Agronomy Journal 97 (2005) 1-6.

[7.] Fageria N, Baligar V, Advances in agronomy 88 (2005) 97-185.

[8.] Snyder C, Bruulsema T, Jensen T, Fixen P, Agriculture, Ecosystems \& Environment 133 (2009) 247-266.

[9.] Hillier J, Hawes C, Squire G, Hilton A, Wale S, Smith P, International Journal of Agricultural Sustainability 7 (2009) 107-118.

[10.] Graham RD. Micronutrient deficiencies in crops and their global significance. Micronutrient deficiencies in global crop production: Springer; 2008. p. 41-61.

[11.] Jones RW, Lunt O, The Botanical Review 33 (1967) 407-426.

[12.] White PJ, Broadley MR, Annals of botany 92 (2003) 487-511.

[13.] White PJ, Journal of Experimental Botany 52 (2001) 891-899.

[14.] Clarkson DT, Plant, Cell \& Environment 7 (1984) 449-456.

[15.] Simon E, New phytologist 80 (1978) 1-15.

[16.] Taylor MD, Locascio SJ, Journal of plant nutrition 27 (2004) 123-139.

[17.] Kirkby E, Pilbeam D, Plant, Cell \& Environment 7 (1984) 397-405.

[18.] Raese JT, Drake SR, Journal of plant nutrition 16 (1993) 1807-1819.

[19.] Auernhammer H, Computers and electronics in agriculture 30 (2001) 31-43.

[20.] Robert P, Plant and soil 247 (2002) 143-149.

[21.] Bradfield E, Spincer D, Journal of the Science of Food and Agriculture 16 (1965) 33-38.

[22.] Wolf B, Communications in Soil Science and Plant Analysis 13 (1982) 1035-1059.

[23.] Yu P, British journal of nutrition 92 (2004) 869-885.

[24.] Butler HJ, McAinsh MR, Adams S, Martin FL, Analytical Methods 7 (2015) 4059-4070.

[25.] Butler HJ, Ashton L, Bird B, Cinque G, Curtis K, Dorney J, et al., Nature protocols 11 (2016) 664-687.

[26.] Schulz H, Baranska M, Vibrational Spectroscopy 43 (2007) 13-25.

[27.] Schulz H, Özkan G, Baranska M, Krüger H, Özcan M, Vibrational Spectroscopy 39 (2005) 249-256.

[28.] Baranski R, Baranska M, Schulz H, Planta 222 (2005) 448-457.

[29.] Ribeiro da Luz B, New Phytologist 172 (2006) 305-318.

[30.] Ord J, Butler HJ, McAinsh MR, Martin FL, Analyst (2016).

[31.] Martin FL, Nat Meth 8 (2011) 385-387.

[32.] Miller L, Carr G, Jackson M, Dumas P, Williams G, Synchrotron Radiation News 13 (2000) 31-38.

[33.] Duncan W, Williams GP, Applied optics 22 (1983) 2914-2923.

[34.] Dumas P, Sockalingum GD, Sulé-Suso J, Trends in Biotechnology 25 (2007) 40-44.

[35.] Vijayan P, Willick IR, Lahlali R, Karunakaran C, Tanino KK, Plant and Cell Physiology (2015) pcv080.

[36.] Bonwell ES, Fisher TL, Fritz AK, Wetzel DL, Vibrational Spectroscopy 48 (2008) 76-81.

[37.] Raab TK, Martin MC, Planta 213 (2001) 881-887.

[38.] Thumanu K, Sompong M, Phansak P, Nontapot K, Buensanteai N, Journal of Plant Interactions 10 (2015) 270-279. 
[39.] Kumar S, Lahlali R, Liu X, Karunakaran C, Applied Spectroscopy Reviews 51 (2016) 466-

483.

[40.] Yu P, McKinnon JJ, Christensen CR, Christensen DA, Marinkovic NS, Miller LM, Journal of agricultural and food chemistry 51 (2003) 6062-6067.

[41.] Heraud P, Caine S, Sanson G, Gleadow R, Wood BR, McNaughton D, New Phytologist 173 (2007) 216-225.

[42.] Dokken KM, Davis LC, Journal of Agricultural and Food Chemistry 55 (2007) 1051710530.

[43.] Dokken KM, Davis LC, Marinkovic NS, Applied Spectroscopy Reviews 40 (2005) 301-326.

[44.] Bonnier F, Petitjean F, Baker MJ, Byrne HJ, Journal of biophotonics 7 (2014) 167-179.

[45.] Tobin MJ, Puskar L, Barber RL, Harvey EC, Heraud P, Wood BR, et al., Vibrational Spectroscopy 53 (2010) 34-38.

[46.] McAinsh MR, Clayton H, Mansfield TA, Hetherington AM, Plant Physiology 111 (1996) 1031-1042.

[47.] Hoagland DR, Arnon DI, Circular California Agricultural Experiment Station 347 (1950).

[48.] WEYERS JDB, TRAVIS AJ, Journal of Experimental Botany 32 (1981) 837-850.

[49.] Wehbe K, Filik J, Frogley MD, Cinque G, Analytical and bioanalytical chemistry 405 (2013) 1311-1324.

[50.] Trevisan J, Angelov PP, Scott AD, Carmichael PL, Martin FL, Bioinformatics (2013) btt084.

[51.] Martin FL, Kelly JG, Llabjani V, Martin-Hirsch PL, Patel II, Trevisan J, et al., Nature protocols 5 (2010) 1748-1760.

[52.] Daley CM, (2008).

[53.] Baker MJ, Trevisan J, Bassan P, Bhargava R, Butler HJ, Dorling KM, et al., Nature protocols 9 (2014) 1771-1791.

[54.] Hughes C, Gaunt L, Brown M, Clarke NW, Gardner P, Analytical Methods 6 (2014) 10281035.

[55.] Jones L, Milne JL, Ashford D, McCann MC, McQueen-Mason SJ, Planta 221 (2005) 255-

264.

[56.] Faolain EO, Hunter MB, Byrne JM, Kelehan P, McNamara M, Byrne HJ, et al., Vibrational Spectroscopy 38 (2005) 121-127.

[57.] Chatjigakis AK, Pappas C, N.Proxenia, O.Kalantzi, P.Rodis, Polissiou M, Carbohydrate Polymers 37 (1998) 395-408.

[58.] Movasaghi Z, Rehman S, ur Rehman DI, Applied Spectroscopy Reviews 43 (2008) 134-

179.

[59.] Shih M-D, Hsieh T-Y, Jian W-T, Wu M-T, Yang S-J, Hoekstra FA, et al., Plant Science 196 (2012) 152-159.

[60.] Gidman E, Goodacre R, Emmett B, Smith AR, Gwynn-Jones D, Phytochemistry 63 (2003) 705-710.

[61.] Geun Goo B, Baek G, Jin Choi D, II Park Y, Synytsya A, Bleha R, et al., Bioresource Technology 129 (2013) 343-350.

[62.] Brown DM, Zeef LA, Ellis J, Goodacre R, Turner SR, The Plant Cell 17 (2005) 2281-2295.

[63.] Kacurakova M, Capek P, Sasinkova V, Wellner N, Ebringerova A, Carbohydrate Polymers 43 (2000) 195-203.

[64.] Schroeder JI, Allen GJ, Hugouvieux V, Kwak JM, Waner D, Annual review of plant biology 52 (2001) 627-658.

[65.] McAinsh MR, Brownlee C, Hetherington AM, Physiologia Plantarum 100 (1997) 16-29.

[66.] McAinsh M. Water relations of plants: Stomata. In: B. Thomas DM, B. Murray, editor. Plant Encylopedia of Applied Plant Science. Academic Press, London: Academic Press, London; 2003. p. 1459-1466.

[67.] Ng CK-Y, Carr K, McAinsh MR, Powell B, Hetherington AM, Nature 410 (2001) 596-599. 
[68.] McAinsh MR, Evans NH, Montgomery LT, North KA, New Phytologist 153 (2002) 441-

447.

[69.] Shen L, Sun P, Bonnell VC, Edwards KJ, Hetherington AM, McAinsh MR, et al., Frontiers in plant science 6 (2015).

[70.] Coates J, Encyclopedia of analytical chemistry (2000).

[71.] Ashokkumar R, Ramaswamy M, Int J Curr Microbiol Appl Sci 3 (2014) 395-396.

[72.] Sene C, McCann MC, Wilson RH, Grinter R, Plant Physiology 106 (1994) 1623-1631.

[73.] Chen L, Carpita NC, Reiter WD, Wilson RH, Jeffries C, McCann MC, The Plant journal : for cell and molecular biology 16 (1998) 385-392.

[74.] Monti F, Dell'Anna R, Sanson A, Fasoli M, Pezzotti M, Zenoni S, Vib Spectrosc 65 (2013) 36-43.

[75.] Allwood JW, Ellis DI, Goodacre R, Physiologia plantarum 132 (2008) 117-135.

[76.] Wilson RH, Smith AC, Kačuráková M, Saunders PK, Wellner N, Waldron KW, Plant Physiology 124 (2000) 397-406.

[77.] Erukhimovitch V, Hazanovsky M, Huleihel M, Spectroscopy 24 (2010) 609-619.

[78.] Trevisan J, Angelov PP, Carmichael PL, Scott AD, Martin FL, Analyst 137 (2012) 3202-

3215.

[79.] Martin FL, German MJ, Wit E, Fearn T, Ragavan N, Pollock HM, Journal of Computational Biology 14 (2007) 1176-1184.

[80.] Maas E, Grieve C, Plant, Cell \& Environment 10 (1987) 559-564.

[81.] Geraldson C, Soil Science Society of America Journal 21 (1957) 621-625.

[82.] Konno H, Nakashima S, Maitani T, Katoh K, Physiologia Plantarum 107 (1999) 287-293. 
Figure 1. Brightfield images obtained from an unfixed abaxial epidermis (A), and a fixed sample (B), of C. communis gown at optimal (200 ppm) Ca. Stomatal guard cells (GCs) can be identified in both samples, although at a higher frequency in isolated epidermis, due to the simplicity of this approach for their isolation
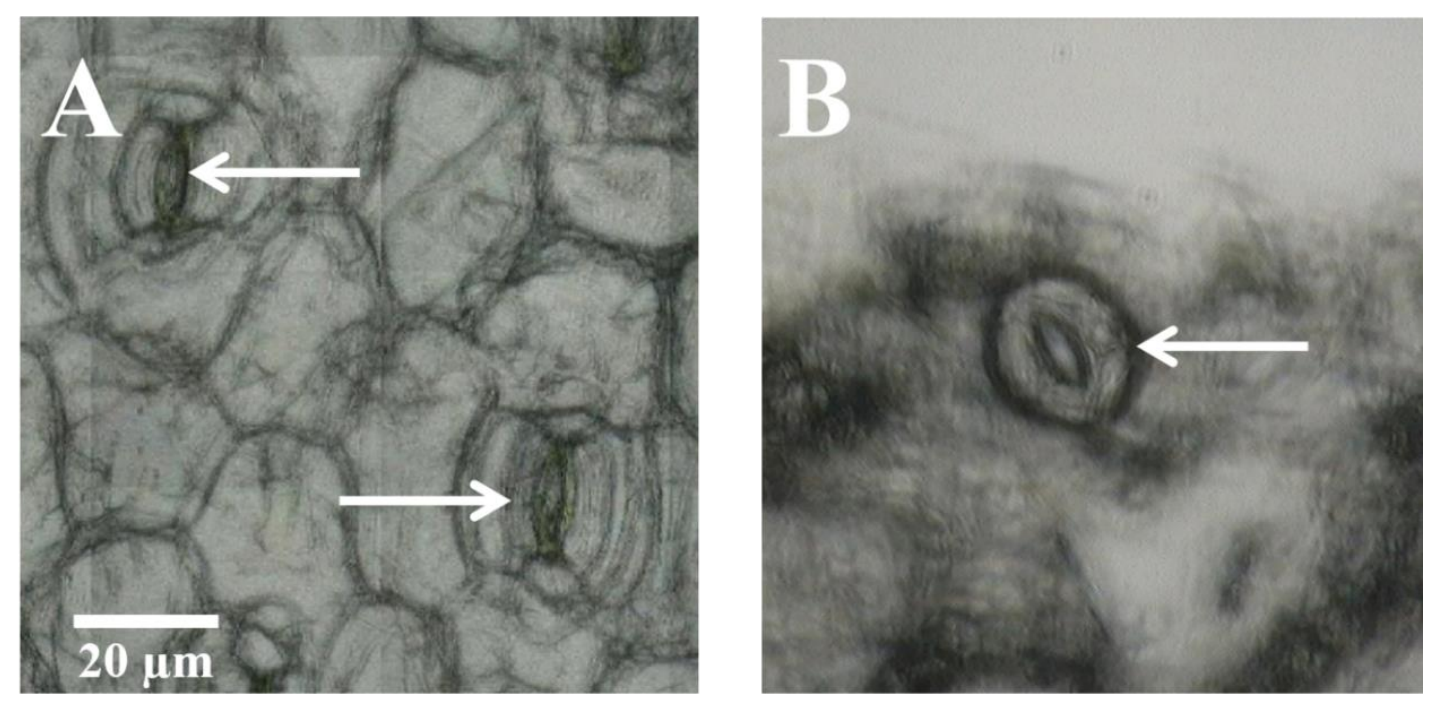
Figure 2. A comparison of pre-processed spectra from unfixed isolated abaxial epidermis and formalin-fixed paraffin embedded tissue from C. communis. Spectra were cut to the fingerprint region $\left(1800-900 \mathrm{~cm}^{-1}\right)$, first order differentiated, vector normalised and offset for clarity.

Dashed markers indicate the top five statistically significant wavenumbers where the gradient is maximum $(\mathrm{y}=0)$.

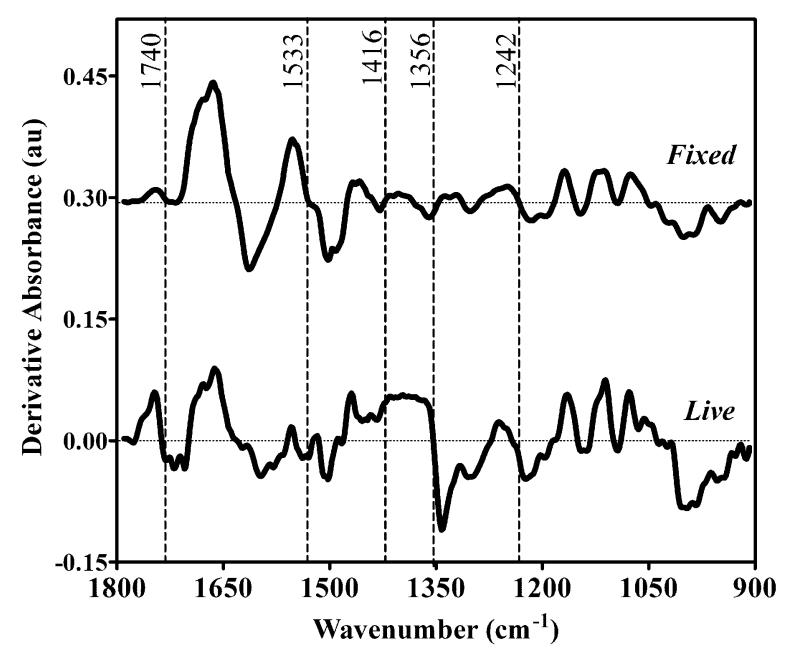


Figure 3. SR-FTIR spectral analysis of unfixed abaxial epidermis from C. communis. (A) Preprocessed spectra from guard cells (GCs) that surround the stomatal pore are compared with surrounding ECs to identify differences in biomolecular composition. Spectra were cut to the fingerprint region $\left(1800-900 \mathrm{~cm}^{-1}\right)$, first order differentiated, vector normalised and offset for clarity, whilst dashed markers indicate the wavenumber regions that most discriminate between the two classes. (B) A 2-dimension scores plot of cross validated PCA-LDA (leave-one-out) to compare the suitability GCs $(\boldsymbol{\Delta} \bullet \boldsymbol{\square})$ and $\mathrm{ECs}(\Delta \circ \square)$ as screening targets for detection of $\mathrm{Ca}$ deficiencies. $200 \mathrm{ppm}$ is defined as optimal conditions, whereas 0 ppm is defined as Ca deficient.
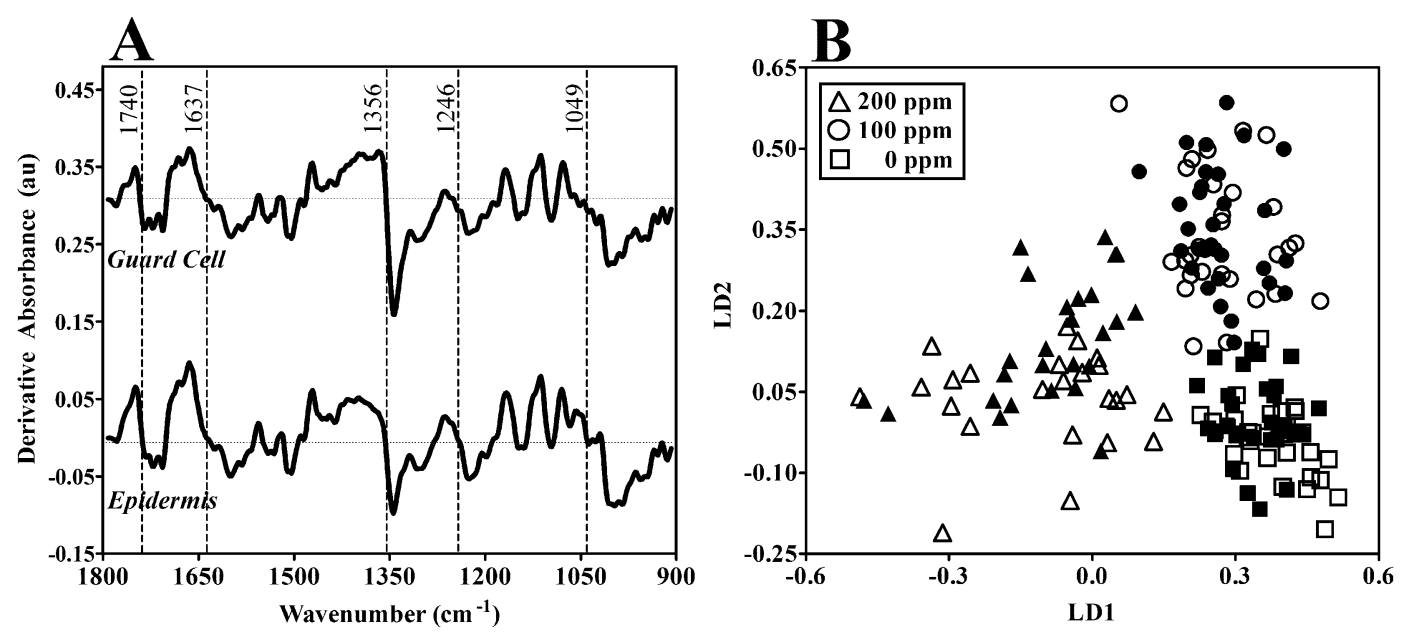
Figure 4. Pre-processed spectra comparing the effects of varying $\mathrm{Ca}$ availabilities in guard cells (GCs) (A) and epidermal cells (ECs) (B) from unfixed epidermal peels; additional to fixed tissue samples (C) samples. Spectra were cut to the fingerprint region $\left(1800-900 \mathrm{~cm}^{-1}\right)$, first order differentiated, vector normalised and offset for clarity, whilst dashed markers indicate the wavenumber regions that most discriminate between the three $\mathrm{Ca}$ treatment classes.
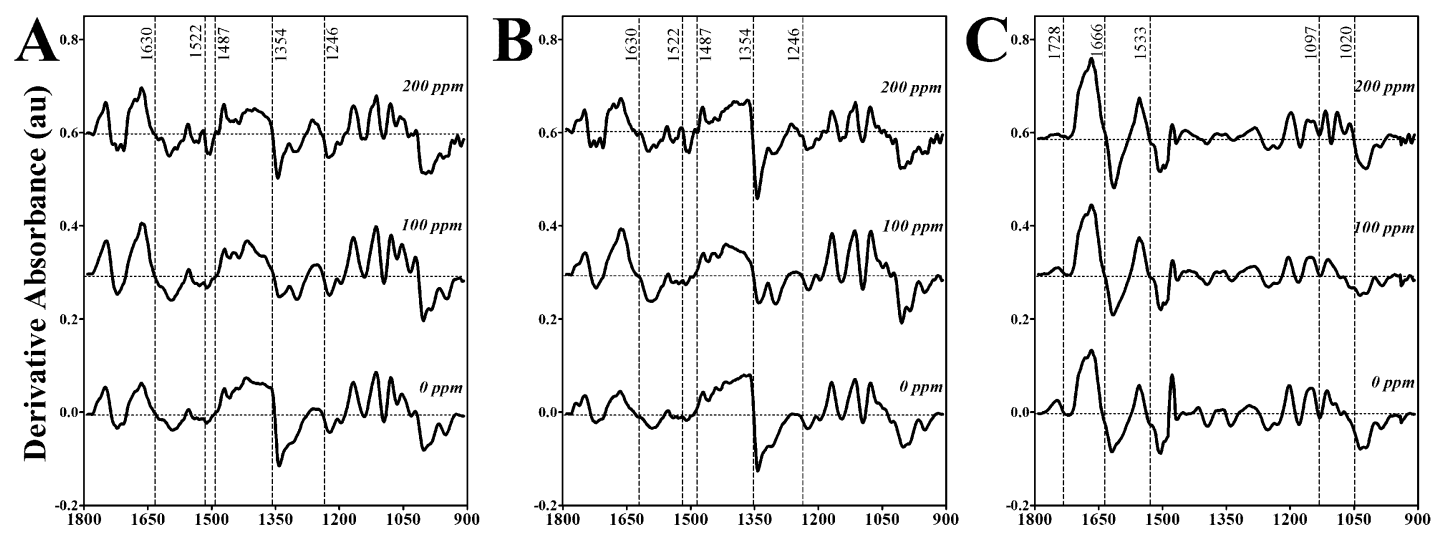

Wavenumber $\left(\mathrm{cm}^{-1}\right)$ 
Figure 5. Leave-one-out cross validated PCA-LDA analysis of both fixed and unfixed $C$. communis samples. (A), (C) and (E) display the 2-dimensional scores plots from guard cells (GCs), epidermal cells (ECs) and fixed tissue at three Ca concentrations ( $\boldsymbol{\Delta} 200 \mathrm{ppm}, \bullet 100$ ppm, and 0 ppm), whilst (B), (D) and (F) show the corresponding first and second linear discriminant loadings from GCs, ECs and fixed tissue, respectively. The most discriminating wavenumbers are indicated with a dashed line for each individual loading.
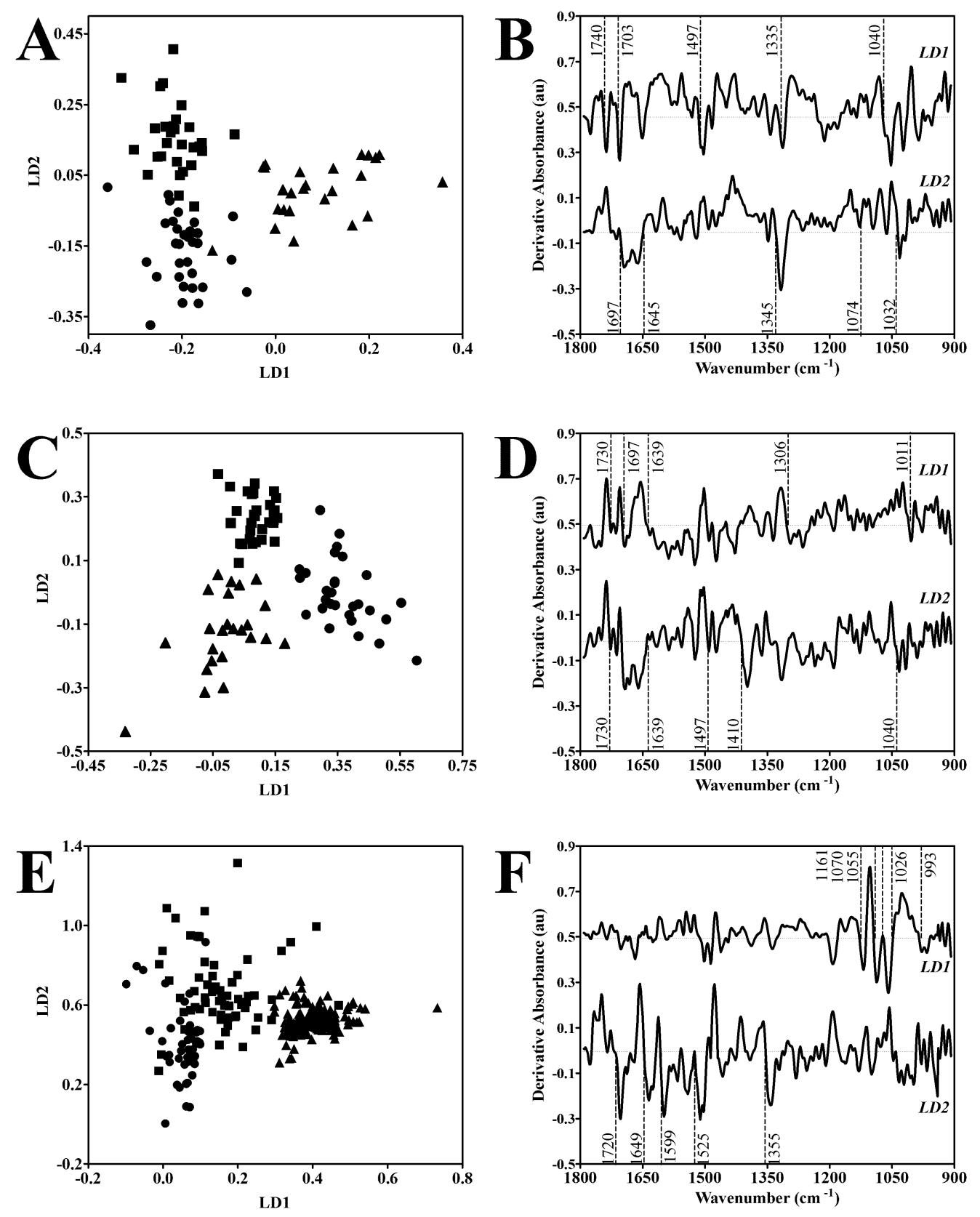
Table 1. Discriminating spectral regions derived from Figure 3, 4 and 5 with tentative molecular assignments, and description of the direction of change in regards to the data class.

\begin{tabular}{|c|c|c|c|}
\hline $\begin{array}{l}\text { Wavenumber } \\
\left(\mathrm{cm}^{-1}\right)\end{array}$ & Tentative Band Assignment & Ref. & Description \\
\hline \multirow[t]{2}{*}{1740} & $v(\mathrm{C}=\mathrm{O})$ polysaccharide, esterified pectin, lipids & {$[57,58]$} & $\uparrow$ Live \\
\hline & & & $\uparrow \mathrm{GC}$ \\
\hline 1728 & $v(C=O)$ lipid, polysaccharide, esterfied pectin, cutin & {$[29,58]$} & $\uparrow$ Deficient* \\
\hline 1637 & Amide I & {$[58]$} & $\uparrow \mathrm{GC}$ \\
\hline 1635 & $\beta$-sheet of amide I & {$[41,58]$} & $\downarrow$ Deficient* \\
\hline 1630 & $v(\mathrm{C}=\mathrm{O})$ and ring breathing, $\beta$-sheet of amide $\mathrm{I}$ & {$[41,59]$} & $\downarrow$ Deficient \\
\hline 1533 & Amide II, $\mathrm{C}=\mathrm{N}$ & {$[60]$} & $\downarrow$ Live \\
\hline 1522 & Amide II, $\mathrm{C}=\mathrm{N}, \mathrm{C}=\mathrm{C}$ & [58] & $\downarrow$ Deficient \\
\hline 1487 & $v(\mathrm{C}=\mathrm{C}), \delta(\mathrm{C}-\mathrm{H})$, Amide II & {$[26,58]$} & $\downarrow$ Deficient \\
\hline 1416 & $\delta(\mathrm{NH}), \delta(\mathrm{CH}), v(\mathrm{C}-\mathrm{N})$ polysaccharides, unesterfied pectin & {$[55,58]$} & $\uparrow$ Live \\
\hline \multirow[t]{2}{*}{1356} & $\delta(\mathrm{C}-\mathrm{OH})$ polysaccharide & [61] & $\uparrow$ Live \\
\hline & & & $\downarrow \mathrm{GC}$ \\
\hline 1354 & $v(\mathrm{C}-\mathrm{O}), \delta(\mathrm{C}-\mathrm{H}), \delta(\mathrm{C}-\mathrm{OH})$, pectin, cellulose & {$[26,61]$} & $\uparrow$ Deficient \\
\hline \multirow[t]{2}{*}{1246} & $v(\mathrm{C}-\mathrm{O})$ cellulose and hemicellulose, asymmetric $v\left(\mathrm{PO}_{2}^{-}\right)$ & {$[40,58]$} & $\uparrow \mathrm{GC}$ \\
\hline & & & $\downarrow$ Deficient \\
\hline 1242 & Asymmetric $v\left(\mathrm{PO}_{2}{ }^{-}\right)$, Amide III & [58] & $\uparrow$ Live \\
\hline 1097 & $v(\mathrm{C}-\mathrm{O})$ carbohydrate, asymmetric $v\left(\mathrm{PO}_{2}^{-}\right)$ & {$[58,62]$} & $\uparrow$ Deficient* \\
\hline 1049 & $v(\mathrm{C}-\mathrm{O}), \delta(\mathrm{C}-\mathrm{OH})$ carbohydrate & {$[58,63]$} & $\uparrow \mathrm{GC}$ \\
\hline 1020 & $v(\mathrm{C}-\mathrm{O}), v(\mathrm{C}-\mathrm{C}), \delta(\mathrm{C}-\mathrm{OH})$ polysaccharides, pectin, & {$[26,58]$} & $\downarrow$ Deficient* \\
\hline
\end{tabular}

* in fixed tissue 
Table 2. Discriminating biomarkers of Ca deficiency as derived from PCA-LDA loadings plots of SR-FTIR spectra of unfixed and fixed $C$. communis samples exposed to low Ca availabilities.

\begin{tabular}{|c|c|c|}
\hline Wavenumber $\left(\mathrm{cm}^{-1}\right)$ & Tentative Band Assignment & Ref. \\
\hline 1740 & $v(\mathrm{C}=\mathrm{O})$ polysaccharide, esterified pectin, lipids & {$[57,58]$} \\
\hline 1730 & $\mathrm{v}(\mathrm{C}=\mathrm{O})$ ester, lipid, lignin & {$[41,58]$} \\
\hline 1720 & $v(\mathrm{C}=\mathrm{O})$ unsaturated ester, pectin & {$[27]$} \\
\hline 1703 & $v(\mathrm{C}=\mathrm{O})$ & [71] \\
\hline 1697 & $v(\mathrm{C}=\mathrm{O})$ & {$[58]$} \\
\hline 1649 & $v(\mathrm{C}=\mathrm{O}), v(\mathrm{C}=\mathrm{N})$ Amide $\mathrm{I}$ & {$[40,60,72]$} \\
\hline 1645 & Amide I & {$[58]$} \\
\hline 1639 & Amide I & {$[58]$} \\
\hline 1599 & $v(\mathrm{COO}-)$ pectin, carboxylic acids, $v(\mathrm{C}=\mathrm{C})$ lignin & {$[41,73,74]$} \\
\hline 1525 & Amide II, $\mathrm{C}=\mathrm{N}, \mathrm{C}=\mathrm{C}$ & {$[27,58]$} \\
\hline 1497 & $\delta(\mathrm{C}-\mathrm{H})$ Amide II & {$[26]$} \\
\hline 1410 & $\delta(\mathrm{NH}), \delta(\mathrm{CH}), v(\mathrm{C}-\mathrm{N})$ polysaccharides & {$[55,58]$} \\
\hline 1355 & $\delta(\mathrm{C}-\mathrm{OH})$ polysaccharide & {$[61]$} \\
\hline 1345 & Carbohydrate & {$[75]$} \\
\hline 1335 & $\delta(\mathrm{CH})$ polysaccharides, pectin, cellulose & {$[58]$} \\
\hline 1306 & Amide III & {$[58]$} \\
\hline 1161 & $v(\mathrm{C}-\mathrm{OH}), v(\mathrm{C}-\mathrm{O}-\mathrm{C})$ polysaccharide, cellulose & {$[43,62,73]$} \\
\hline 1074 & $v(\mathrm{CO}), v(\mathrm{CC})$ & {$[58]$} \\
\hline 1070 & $v(\mathrm{CO}), v(\mathrm{CC})$ cellulose & {$[76]$} \\
\hline 1055 & $v(\mathrm{CO}), v(\mathrm{CC}), \delta(\mathrm{C}-\mathrm{OH})$, pectin & {$[76]$} \\
\hline 1040 & $v(\mathrm{CO}), v(\mathrm{CC})$, cellulose & {$[76]$} \\
\hline 1032 & $v\left(\mathrm{O}-\mathrm{CH}_{3}\right)$ cellulose & {$[29,58]$} \\
\hline 1026 & $v(\mathrm{CO}), v(\mathrm{CC})$ cellulose & [74] \\
\hline 1011 & $v(\mathrm{CO}), v(\mathrm{CC}), \delta(\mathrm{C}-\mathrm{OH})$, pectin & {$[26,58]$} \\
\hline 933 & Carotenoid, carbohydrate & {$[58,77]$} \\
\hline
\end{tabular}


Table. 3 Classification rates of each tissue sample and Ca treatment (\%) as derived from principal component analysis (PCA) fed linear discriminant classifiers, using a leave-one-out approach and 10 $k$-folds

Classification Rate $(\%) \pm \mathrm{SE}$

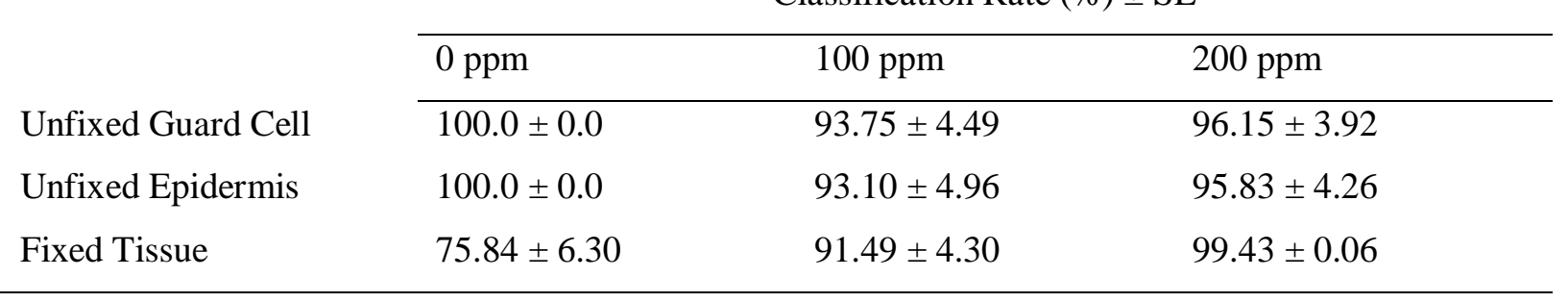

